
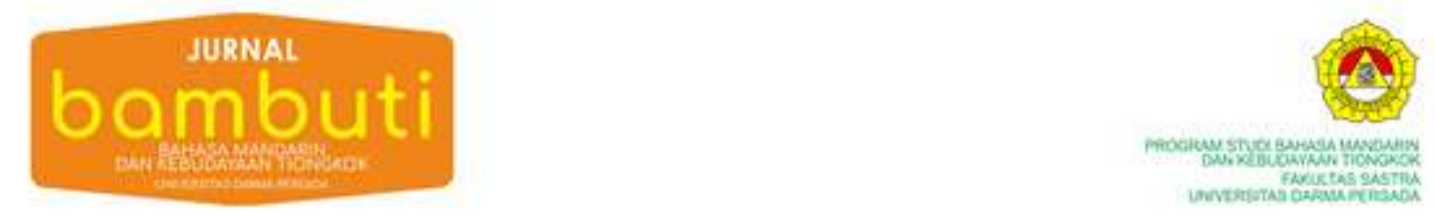

\title{
TRADISI PENGHORMATAN DEWA DALAM MASYARAKAT TIONGHOA BEKASI
}

\author{
Celerina Dewi Hartati \\ email: c.dewihartati@gmail.com
}

Bahasa Mandarin dan Kebudayaan Tiongkok, Universitas Darma Persada

\begin{abstract}
This article discusses the practice of the cult of temple"s deity. This cult is said to be a reinvented tradition. The tradition is created because it is formed by the elements that come from the original tradition. By tracing the process of discovering the Hobsbawm tradition from the sacred and profane aspects of Durkheim and its relation to totemism, it is evident that this tradition has a new form and function. The original function of tradition was to strengthen identity, but the new function of the reinvented tradition appears to be an integrative function. The reinvented tradition also occurs in an effort to attract public interest or attention to make it more popular in the community. The temple community carries out an invented traditional process so that the tradition of the cult becomes more attractive, and is preferred more popular, through the appearance of entertainment shows at festivals.
\end{abstract}

Keywords : cult; sacred; profane; reinvented tradition

\section{Pendahuluan}

Tulisan ini berisi tradisi yang ditemukan dalam agama masyarakat Tionghoa Indonesia. Orang Tionghoa memiliki pandangan dunia spiritual di mana melihat konsep Tian, dewa, roh, dan leluhur disembah untuk menjaga hubungan serta untuk mendapatkan tujuan yang ingin dicapai. Penghormatan ini dapat dipadukan dalam kepercayaan agama apapun karena penghormatan dewa merupakan tradisi yang menjadi dasar kepercayaan agama masyarakat Tionghoa. Agama rakyat atau agama popular merupakan komponen yang sangat penting dalam lanskap keagamaan Tionghoa. Agama rakyat Tionghoa sering ditafsirkan dengan ciri sinkretis antara Konfusianisme, Taoisme, dan Buddha, sebagaimana didefinisikan oleh misionaris Jesuit yang datang ke China pada awal 1600-an (Soothill, 1913), dan sebagai berbagai aktivitas takhayul yang dilakukan oleh massa ( de Groot, 1910; Granet, 1922). Selain itu, agama rakyat juga didefinisikan sebagai bagian dari keseluruhan budaya Tionghoa (Freedman, 1974) dan juga sebagai proses pembentukan makna yang dapat diubah (Bell 1989; Clart 2007; Weller 1987). Agama rakyat Tionghoa dapat didefinisikan menurut dua konsep, sebagai berikut:

1. Suatu bentuk agama yang dianut oleh hampir semua orang Tionghoa, tanpa memandang status sosial dan ekonomi, tingkat pendidikan, wilayah, atau identifikasi agama tertentu seperti 1) 
pemakaman dan upacara ritual khas Tionghoa, termasuk ritual yang berhubungan dengan dunia orang mati; 2) festival Tahun Baru, yang menandai peralihan tidak hanya dalam kehidupan individu dan keluarga, tetapi juga dalam siklus tahunan kosmos; dan 3) ritual konsultasi media roh baik di rumah maupun di kuil untuk memecahkan masalah seperti penyakit keluarga, mimpi buruk, masalah bisnis, roh jahat, atau kemalangan lainnya.

2. Agama kelas bawah, sebagai lawan dari agama elit atau umum. Di masa lalu, hanya kaisar dan elit di China yang bisa memuja Tian sebagai penguasa tertinggi struktur para dewa; rakyat jelata tidak bisa menyembah Tian, hanya dewa dan leluhur.

Yang dan Hu (2012: 508-510) membedakan tiga jenis agama rakyat, yaitu individu, komunal, dan sektarian. Contoh dari agama individu adalah cara dalam kehidupan sehari-hari, orang Tionghoa menghormati leluhur dan makhluk tertinggi seperti orang suci, dewa, dan Tian Digong atau yang disebut Yuhuang Shang Di (Kaisar Giok) yang menurut kepercayaan orang Tionghoa adalah pelaksana tertinggi pemerintahan alam semesta, juga dikenal sebagai dewa tertinggi. Banyak orang Tionghoa yang mempraktikkan agama individu terlibat dalam praktik ramalan di klenteng, yang dikenal sebagai ciamsi. Agama komunal mengacu pada aktivitas keagamaan atau ritual dan spiritual yang didasarkan pada komunitas: misalnya, penghormatan terhadap dewa-dewa lokal yang melayani kepentingan komunitas lokal. Agama sektarian mirip dengan agama institusional seperti Buddha atau sekte Buddha seperti Chan, Tiantai, Huayan, Tanah Suci, dan lain-lain yang memiliki struktur organisasi yang relatif stabil, dengan anggotanya berdasarkan komunitas lokal, dan sistem kepercayaan yang cenderung lebih sistematis. Banyak kelompok sektarian di Taiwan memiliki doktrin agama dan struktur organisasi formal, seperti kelompok Zhengyitao 正一道 (salah satu aliran dalam Taoisme).

Dasar kepercayaan orang Tionghoa adalah apa yang disebut “Jing Tian Zun Zu “敬天尊祖 yang berarti "memuliakan langit (Tuhan) dan menghormati leluhur." Dasar ini kemudian memegang banyak peran dalam berbagai upacara keagamaan dan menjadi inti dari budaya spiritual Tionghoa. $Z u$ atau leluhur juga bisa disebut sebagai shen (dewa). Menurut konsep dewa dalam budaya Tionghoa ini, siapa pun yang memiliki jasa dan kontribusi kepada seseorang dan keluarganya dianggap sebagai dewa. Sementara $z u$ (leluhur) disembah dan dihormati hanya oleh satu keluarga, shen dihormati dan disembah oleh banyak keluarga, yaitu dipuja oleh masyarakat. Hubungan timbal balik antara Tian dan manusia, shen atau zu dengan manusia menjadi akrab dan 
penuh perasaan. Biasanya orang memberi hormat (bai ) setiap kali bertemu dengan dewa di kelenteng meskipun mereka tidak tahu siapa dewa yang mereka temui. Penghormatan dewa-dewa ini, termasuk penghormatan terhadap leluhur, dan makhluk tertinggi, semuanya merupakan elemen yang sangat penting dari agama populer Tiongkok.

Penghormatan terhadap dewa adalah bentuk penghormatan awal di Tiongkok. Menurut catatan sejarah, penghormatan terhadap dewa-dewa di Tiongkok sudah ada sejak zaman Dinasti Shang (1600-1406 SM). Dewa-dewa ini mewakili kekuatan alam, seperti matahari, hujan, dan bulan, misalnya Yu-huang, dewa langit; Fei Lian dan Feng Po, dewa angin; Lei Kung atau Lei zi, dewa petir; Chang E, dewi bulan; Gong gong, dewa banjir; Han, dewa sungai; Hou Ji, dewa millet; dan dewa-dewa lain yang bertanggung jawab atas sungai dan gunung. Semua dewa ini telah disembah sejak Dinasti Shang, dengan dewa-dewa lain menjadi terkenal setelah periode itu.

Orang yang beribadah di kelenteng umumnya penganut Samkauw/ sanjiao atau Tridharma. Tridharma di Indonesia dapat dibagi menjadi dua kelompok besar: sinkretisme (sering disebut sanjiao heyi (三教 合一), yang mengacu pada kesetaraan, atau sanjiao pingdeng (三教 平等). Berbeda dengan penghormatan leluhur yang dilakukan di rumah, penghormatan terhadap dewa dilakukan di kelenteng sebagai pusat kegiatan yang memiliki fungsi tradisional, ritual, spiritual, kontrol sosial, dan hiburan.

Banyak orang Tionghoa Indonesia adalah Tridharma / Sanjiao dan menggabungkannya dengan kepercayaan syamanisme (wujiao ). Di beberapa tempat juga bisa terjadi interaksi atau peleburan dengan kepercayaan lokal. Hal ini wajar karena kepercayaan dasar orang Tionghoa adalah politeisme, penghormatan terhadap leluhur dan pragmatisme. Tulisan ini menggunakan studi kasus upacara ulang tahun dewa yang diadakan di Bekasi, untuk menganalisis penghormatan dewa sebagai inti dari agama Cina. Salah satu klenteng terbesar dan tertua di Bekasi adalah Klenteng Hok Lay Kiong (福來宫), yang terletak di Jalan Kenari I. Usia kelenteng ini diperkirakan sekitar 250 hingga 300 tahun. Menurut salah satu informan yang bekerja untuk kelenteng ini. di atap kelenteng (tiongcit) terdapat tulisan 1.818 angka yang menjadi perkiraan untuk memperkirakan usia kelenteng tersebut.

Kelenteng ini dikelola oleh Yayasan Pancaran Tri Dharma. Dewa utama kelenteng ini adalah Xuan Tian Shangdi (玄天上帝 / Hian Thian Siang Tee), penguasa langit utara. Penghormatan terhadap Xuan Tian Shangdi sangat meluas, tidak hanya di Cina bagian selatan, tetapi juga di Cina bagian utara, Malaysia, Taiwan, dan juga di Indonesia. Selain Xuan Tian Shangdi, kelenteng ini 
juga menempatkan San Guan Dadi, Guan Gong, Guanyin Pusa, Cai Shenye, Fu De Zhengshen, Er Langshen, Taisuiye, Baosheng Dadi, Zaoshen dan juga Buddha.

Tradisi pada umumnya selalu dikontraskan dengan modernitas, modernitas berkaitan dengan hal-hal yang rasional. Namun, dalam kasus penghormatan dewa pada masyarakat Tionghoa Bekasi, tradisi sejajar dengan modernitas. Modernitas tidak menghilangkan tradisi, tradisi dapat bertahan dan terus berkembang melalui proses tradisi yang diciptakan. Penghormatan terhadap dewa dapat dipadukan dalam kepercayaan agama apa pun karena merupakan tradisi yang menjadi dasar keyakinan agama orang Tionghoa. Penghormatan dewa dapat bertahan dan dipraktikkan oleh orang Tionghoa karena orang Tionghoa pada umumnya tidak menggunakan agama sebagai identitasnya.

Emile Durkheim mendefinisikan agama dari sudut pandang yang sakral. Artinya agama adalah kesatuan sistem kepercayaan dan praktik yang berhubungan dengan yang sakral. Semua keyakinan agama, baik yang sederhana maupun yang kompleks, menunjukkan ciri umum yang memisahkan antara yang sakral dan yang profan. Hal-hal sakral selalu ditafsirkan sebagai yang superior dan berkuasa; dalam kondisi normal mereka tidak tersentuh dan selalu dihormati. Hal-hal yang profan adalah bagian dari kehidupan sehari-hari dan hanya hal-hal biasa.

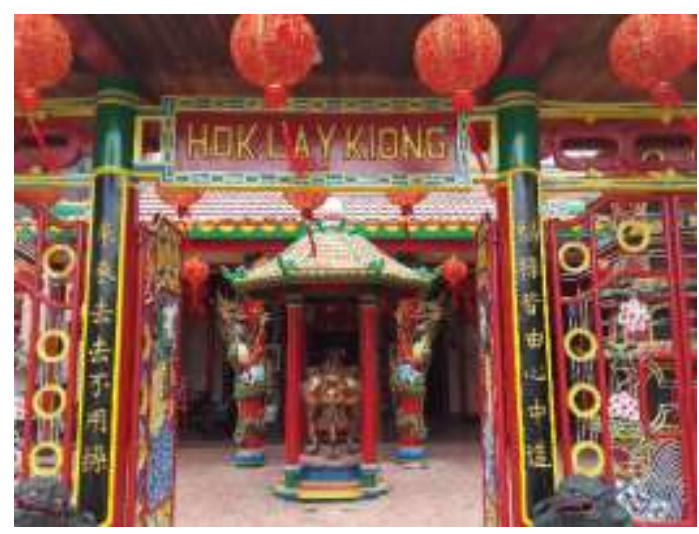

Gambar 1. Kelenteng Hok Lay Kiong Sumber : pribadi

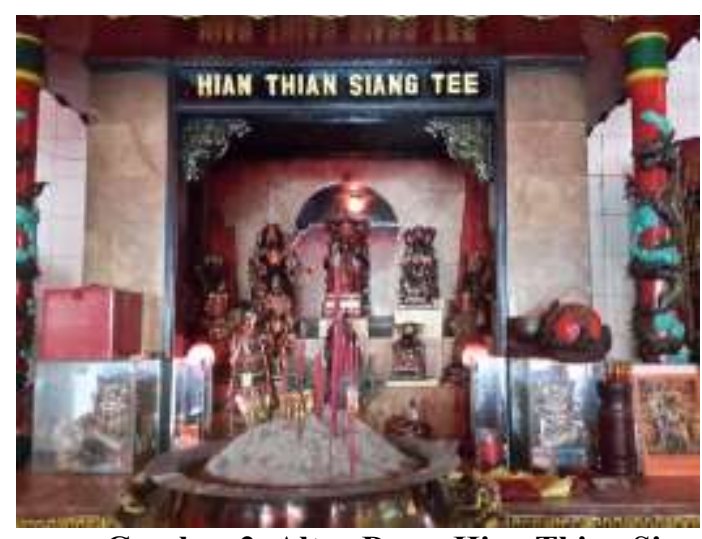

Gambar 2. Altar Dewa Hian Thian Siang Tee Sumber : pribadi

\section{Metodologi}

Penelitian ini dilakukan di Klenteng Hok Lay Kiong yang terletak di kota Bekasi. Pengumpulan data dilakukan dengan wawancara mendalam, observasi partisipan, dan studi literatur. Informan adalah orang-orang yang ada di kelenteng, baik yang bekerja di kelenteng maupun yang aktif dalam kegiatan. Sebagai studi etnografi, teknik utama yang digunakan untuk 
mengumpulkan data adalah observasi partisipan. Sebagai metode penelitian, etnografi menghasilkan penggambaran suatu masyarakat yang diteliti dari sudut pandang masyarakat itu sendiri (emik). Partisipasi juga memungkinkan terjadinya resosialisasi, saya sebagai peneliti, terlibat dengan norma-norma dan makna dari kebudayaan yang saya pelajari, dan mempelajari apa yang diperlukan untuk menjadi anggota dalam dunia sosial mereka. Selanjutnya, observasi partisipan memungkinkan untuk mengumpulkan data yang dapat diamati, serta perilaku terkait dan pengalaman langsung.

Wawancara mendalam diperlukan untuk melengkapi observasi partisipan. Memang, dalam praktiknya, ini tidak selalu dapat dipisahkan karena batas antara keduanya tidak selalu jelas. Wawancara adalah cara yang berguna untuk memperjelas, misalnya tata cara, makna sebuah tradisi. Saya juga mempelajari literatur untuk mendapatkan pemahaman tentang sejarah orang Tionghoa Bekasi, serta tradisi penghormatan dewa, dewa-dewa dalam budaya Tionghoa, pemikiran Tiongkok, mitologi, dan pandangan hidup, dan pemahaman mereka tentang dewa.

\section{Tradisi Ulang Tahun Dewa Kelenteng}

Tradisi merupakan cara untuk mengintegrasikan tindakan secara refleksif dengan penataan ruang dan waktu dalam masyarakat. Ia dinamis, karena harus diciptakan kembali oleh setiap generasi baru ketika mengambil alih warisan budaya dari pendahulunya. Tradisi merupakan ciri khas suatu bentuk budaya dalam sesuatu yang dinamis dan berubah. Ditransmisikan, dipelihara, dan tidak hilang, ditransmisikan dari waktu ke waktu, diajarkan dari generasi ke generasi, dan ditunjukkan dan dipercaya pada saat ini. Tradisi menghubungkan masa lalu dan masa kini dan menunjukkan perubahan dan keberlanjutan. Shahab (2001), dalam penelitiannya tentang komunitas Betawi, menemukan bahwa tradisi terkadang menghasilkan efek atau efek samping yang tidak diharapkan. Bahkan, efek ini seringkali lebih kuat dalam pengaruhnya dan membekas lebih signifikan pada perkembangan masyarakat daripada tujuan yang semula ingin dicapai. Lebih lanjut, Shahab (2001) menekankan bahwa proses penemuan kembali tradisi hanya dapat berhasil jika memiliki efek ke dalam dan ke luar. Secara batin, hasil penemuan kembali tradisi harus mampu memberikan identitas kepada kelompok pemilik. Identitas ini mengacu pada keberadaan kelompok. Secara lahiriah, hasil tradisi yang diciptakan kembali harus dapat diterima oleh kelompok masyarakat lain di luar lingkaran kelompok pemilik. Dengan cara ini, tradisi yang 
diciptakan akan mendapatkan pengakuan sehingga komunitas pemiliknya menjadi kredibel. Menghadirkan yang lama dengan penyesuaian baru menjadi inti dari tradisi yang bertahan.

Penemuan Kembali tradisi adalah tradisi yang dibentuk oleh unsur-unsur penyusunnya yang berasal dari tradisi asal. Tradisi semacam ini dibentuk untuk memenuhi kebutuhan yang ada akan identitas suatu suku atau kelompok masyarakat. Dalam hal ini, tradisi yang diciptakan memiliki bentuk dan fungsi baru. Modernisasi yang terjadi di suatu negara tidak serta merta mengubah seluruh aspek kehidupan manusia secara drastis atau mengikutsertakan seluruh penduduk di dalamnya. Studi yang dilakukan oleh Akintan (2013) di suatu wilayah di Nigeria menunjukkan bahwa praktik keagamaan, seperti festival, dilaksanakan meskipun telah terjadi perubahan karena datangnya agama-agama baru. Perkembangan ilmu pengetahuan dan teknologi tidak mengubah kelompok-kelompok tertentu dalam masyarakat. Beberapa penganut adat tetap dengan agama mereka, dan masih merayakan upacara adat di masa sekarang.

Upacara ritual merupakan acara perayaan penting dalam setiap masyarakat yang hidup bersama untuk waktu yang lama. Penganut agama tradisional melakukan festival tradisional untuk menandai peristiwa sosial dan budaya masyarakat, dan berujung pada serangkaian pertunjukan, hiburan, ritus, dan ritual. Perayaan tradisional bertahan dalam modernitas karena keterkaitan antara tradisi dan modernitas. Dalam kasus penghormatan dewa yang dipraktikkan dalam modernitas, ini menunjukkan upaya manusia untuk tetap berhubungan dengan sesuatu yang sakral, kekuatan gaib, dan saling ketergantungan antara dunia imanen dan transenden. Hubungan antara Tian dan manusia tetap terjalin dan terpelihara dalam modernitas.

Emile Durkheim berpendapat bahwa setiap keyakinan agama selalu membutuhkan pengklasifikasian hal-hal, baik yang konkret maupun gagasan dalam pikiran, dan membaginya menjadi dua kategori yang berlawanan, yaitu sakral dan profan. Pembagian hal-hal ke dalam dua domain ini adalah ciri pembeda utama pemikiran keagamaan dibandingkan dengan sesuatu yang tidak religius. Dengan demikian, keyakinan beragama merupakan representasi yang mengungkapkan esensi dari hal-hal yang sakral (Rudyansjah, 2015: 94). Karena agama adalah fakta sosial, maka agama harus konkrit, dan untuk menjadikannya konkrit, timbul benda, orang, tempat, dan waktu yang dianggap memiliki kekuatan mistik dan kemudian menjadi sakral. Durkheim dengan jelas membedakan agama dari yang sakral dan profan, dan pembagian ini sangat kaku dan tidak sesuai. Sesuatu yang sakral akan tetap sakral, dan tidak bisa berubah menjadi profan dan sebaliknya. Agama terutama terletak pada "suci" karena memiliki pengaruh yang luas, dan 
menentukan kesejahteraan dan kepentingan seluruh anggota masyarakat. Yang profan tidak memiliki pengaruh yang begitu besar dan hanya merupakan refleksi harian dari setiap individu. Dikotomi sakral dan profan bukanlah dikotomi antara yang baik dan yang jahat. Yang sakral dan yang profan tidak bisa saling mengubah dan selalu tetap.

Perbedaan antara konsep sakral dan profan dalam praktik pemujaan dewa-dewa dapat dilihat pada konsep ruang dan waktu. Ruang dan waktu keramat benar-benar nyata, permanen, dan abadi, hidup dalam waktu yang kokoh, dan kembali ke hadirat para dewa. Sebaliknya, ruang dan waktu profan tidak stabil dan ada di dunia profan. Durkheim mengemukakan bahwa benda-benda yang diyakini sacral adalah totem. Bagi manusia, totem secara terminologis menganggap benda atau binatang yang memiliki kekuatan mistik dan melekat pada dunia. Keyakinan agama mengandung aturan perilaku yang dapat menentukan dan mengatur seseorang untuk bersikap baik terhadap keberadaan benda-benda suci. Durkheim percaya bahwa totem adalah kultus yang didirikan dan dikembangkan di masyarakat Australia dan Amerika Utara. Totem adalah penanda kelompok, nama kelompok, dan dipuja oleh kelompok. Totem bukan hanya nama tetapi juga simbol atau tanda. Totem digambar sebagai simbol, diukir di dinding dan perisai, dan dalam masyarakat modern, dicitrakan. Melalui penggunaan totem sebagai simbol kelompok, para anggotanya diingatkan akan keberadaan kelompok mereka; tanpa simbol ini, mereka akan melupakan hubungan mereka satu sama lain. Ketika semua anggota kelompok berkumpul untuk menyembah totem, makna kolektif ditegaskan kembali. Dengan memuja totem, orang memuja kelompok. Dengan cara ini, totem memiliki fungsi integrasi karena mengintegrasikan dan menyatukan berbagai bagian dari sistem sosial.

Tradisi pemujaan dewa dapat dilihat pada perayaan hari lahir dewa utama kelenteng (sejit). Kelenteng Hok Lay Kiong, yang memiliki dewa utama Hian Thian Siang Tee, dirayakan pada hari ketiga bulan ketiga penanggalan Imlek. Perayaan sejit dilaksanakan selama tiga hari. Orang-orang datang untuk berdoa, membawa sajian, makan bersama untuk berkah dan keselamatan (cia pengan). Dalam sejit, orang diberi kertas jimat (kertas $h u$ ) yang berisi tulisan para dewa yang dibuat oleh medium roh. Ukiran tulisan, surat, atau mantra ini diberkati dengan mantra dan cap dewa tertentu. Kertas $h u$ biasanya dibuat di depan altar dewa.

Upacara membuat kertas $h u$ dilaksanakan pada hari ketiga perayaan dan menjadi upacara penutupan. Suasana semakin meriah ketika para medium (tangsin) yang bergantian diiringi musik gendang dan simbal, menunjukkan atraksi dengan melukai lidahnya dengan pedang dan dengan 
darahnya menulis kertas $h u$ dewa Hian Thian Siang Tee. Banyak orang menyebut tradisi ini sebagai "tradisi potong lidah". Darah dari lidah dikumpulkan dalam cawan, dan kemudian tangsin menggunakannya untuk membuat kertas $h u$ sebagai jimat (hu pengan) Proses ini dimulai oleh tangsin utama dan setelah itu tangsin lainnya bergantian membuat hu pengan.

Kertas $h u$ yang merupakan bahan cetakan ini menjadi sakral ketika tangsin menulis di atasnya dengan darahnya menggunakan kuas, sehingga memiliki mantra. Kertas-kertas ini adalah jimat yang dicari orang untuk digunakan atau disimpan untuk tujuan mereka sendiri. Kertas tersebut dapat dibakar, biasanya bila sudah berisi mantra dan doa dewa yang dipuja. Ini dibakar di akhir upacara; nama orang yang meminta pembakaran juga tertulis. $H u$ juga dapat berfungsi sebagai obat, dengan cara dibakar dan abunya ditambahkan ke dalam air atau teh dan minuman lainnya. Menurut salah satu pengurus kelenteng, kertas jerami digunakan untuk $h u$ sehingga tidak berbahaya jika diminum orang. Kertas $h u$ juga dapat dilipat menjadi bentuk segitiga, dan diperoleh dari kelenteng. Kertas $h u$ juga sering diikat di pintu rumah untuk memastikan perlindungan dari roh dan pengaruh jahat. Banyak orang menggunakan $h u$ baik sebagai obat atau disimpan di laci atau dompet. Kertas $h u$ memiliki masa berlaku setidaknya enam bulan dan tidak boleh dibawa ke toilet.

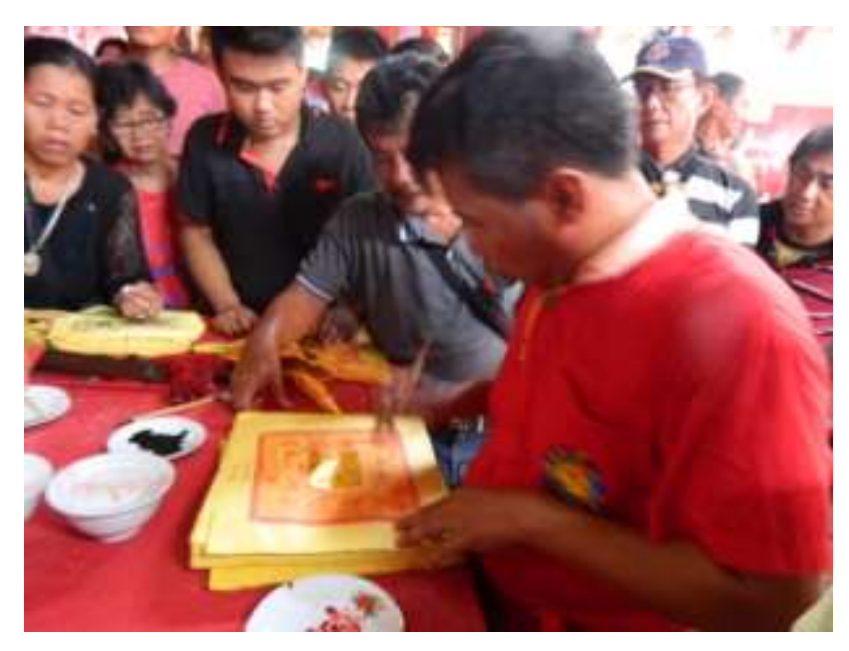

Gambar 3. Tangsin (medium) menulis kertas $h u$ Sumber : Dokumen pribadi

Ada banyak pertunjukan yang diadakan selama sejit, seperti tangsin yang melakukan atraksi berjalan di atas api dan pelelangan barang. Sejit telah menjadi festival kelenteng yang menarik orang untuk datang dan menikmati pertunjukan ini. Ada juga hiburan, seperti orkes gambang kromong dan wayang golek. Pertunjukan ini lebih untuk menghibur pengunjung, tamu yang datang baik untuk berdoa maupun menikmati pertunjukan. Suasana festival kelenteng bisa dirasakan di 
Bekasi karena acara yang dipentaskan, dan banyaknya orang yang berjualan di sekitar kelenteng. Suasana pasar malam sangat meriah dengan iringan orkes gambang keromong. Anak-anak muda sepertinya kumpul dan kali ini sering menjadi waktu reuni. (Hartati, 2017 : 523). Sepanjang jalan menuju kelenteng, kerumunan pedagang menjual barang-barang seperti perlengkapan sembahyang kelenteng, suvenir, makanan, dan minuman.

Instruksi Presiden No. 14 Tahun 1967, melarang semua tradisi Tionghoa, sehingga perayaan sejit tidak dapat dilaksanakan. Sebelum masa Orde Baru festival ini sangat meriah dan digelar secara terbuka. Ketika pembatasan tradisi budaya Tionghoa dimulai, menurut salah satu medium (tangsin), festival sejit dilakukan secara sembunyi-sembunyi. Dia mengatakan orang-orang mempersiapkan festival secara diam-diam, seolah-olah bermain petak umpet dengan pihak berwenang. Dijelaskannya, pada suatu kesempatan, panitia sudah menyiapkan dan mengorganisir upacara injak bara, namun tiba-tiba polisi datang sehingga harus segera menutup tempat untuk upacara injak bara. Saat ini, tradisi Tionghoa dapat diberlakukan secara terbuka di ruang publik dan festival diadakan dengan meriah, memenuhi fungsi keagamaan, sosial, budaya, dan seni. Oleh karena itu, festival ulang tahun dewa sebagai tradisi masih dipertahankan dalam modernitas.

Hari pertama pelaksanaan sejit dimulai pada pukul 09.00 WIB. dengan pengaturan meja di depan altar dewa utama. Meja altar dipenuhi patung singa, buah-buahan, kue ulang tahun, kue kering, dan sejumlah barang yang akan dilelang. Pelelangan barang ini merupakan bentuk tradisi yang diciptakan kembali. Barang-barang yang dulunya barang sehari-hari biasa (profan) menjadi sesuatu yang sakral setelah ditempel dengan kertas $h u$. Dikatakan sebagai tradisi yang diciptakan kembali karena tidak semua tempat di Tiongkok memiliki tradisi ini. Tidak ada tradisi seperti itu di Cina utara, sementara di Cina selatan, beberapa kelenteng memegang tradisi ini. Kelenteng Hok Lay Kiong awalnya tidak melakukan pelelangan barang, tetapi sejak beberapa orang Hakka terlibat dalam pengelolaan kelenteng maka tradisi lelang barang dilakukan di kelenteng ini.

Hasil lelang semuanya diserahkan kepada yayasan. Barang-barang yang dilelang bersifat profan tetapi dalam konteks ruang yaitu kelenteng dan dalam konteks waktu yaitu sejit, barangbarang profan menjadi sakral melalui penggunaan percikan air berkah dan juga kertas jimat. Selain itu, kertas jimat yang ditulis oleh tangsin dalam ritual ini dipercaya sebagai kertas dewa. Ketika diberi mantra dewa, maka itu menjadi sesuatu yang sakral. Pada hari pertama, ada tradisi tatung yang merupakan bagian dari tradisi Hakka. Proses reinvented tradition di sini dipandang sebagai ciri perpaduan antara tradisi Hokkian dan Hakka. Orang Bekasi Tionghoa pada umumnya adalah 
orang Hokkian, tetapi karena globalisasi, banyak orang Hakka di Bekasi. Parade Tatung diadakan dalam rangkaian ritual ini untuk merayakan dewa Xuan Tian Shangdi.

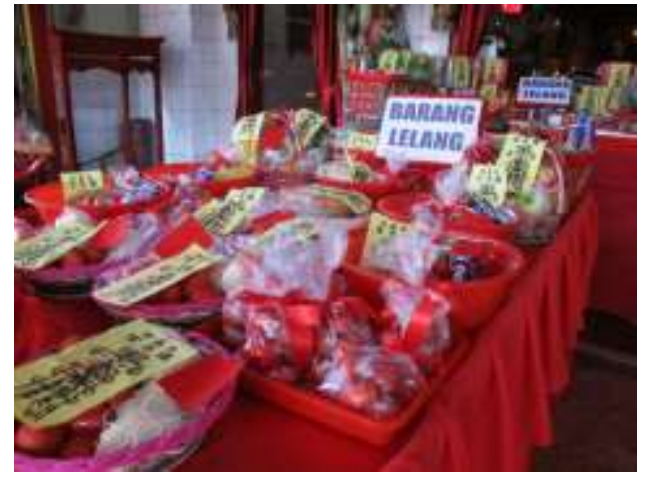

Gambar 4 Barang Lelang

Sumber : Dokumentasi pribadi

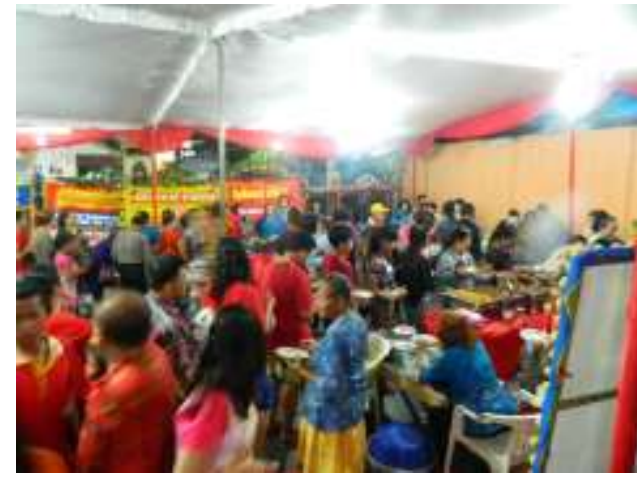

Gambar 5. Suasana cia peng an Sumber : Dokumentasi pribadi

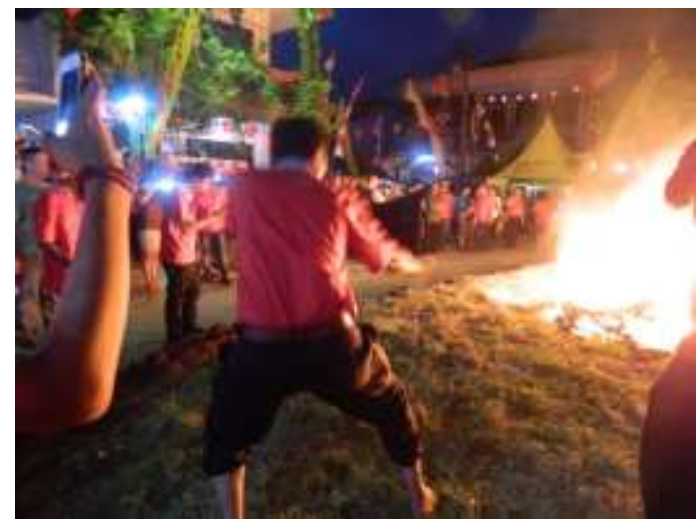

Gambar 7. Upacara injak bara Sumber : dokumen pribadi

Akulturasi tradisi Hokkien dan Hakka muncul dalam ritual ini, dengan tatung mewakili tradisi Hakka dan tangsin mewakili tradisi Hokkian. Baik tatung maupun tangsin adalah medium yang dipentaskan dalam ritual ini. Ada gambang kromong dan wayang golek Bekasi yang dipentaskan selama tiga hari sebagai hiburan. Semua ini adalah tradisi yang diciptakan kembali karena mereka mengambil bentuk dan fungsi baru. Bentuk barunya adalah munculnya tradisi Hokkien dan Hakka yang dilakukan bersama dalam ritual ini. Fungsi asli tradisi adalah untuk memperkuat identitas, tetapi fungsi baru dari tradisi yang diciptakan kembali tampaknya merupakan fungsi integratif.

Xuantian Shangdi ( Hian Thian Siang Tee) terhubung dengan kura-kura suci, juga disebut kura-kura ilahi atau kura-kura di Cina kuno. Xuan Tian Shangdi, juga disebut Xuan Wu dan Xuanwu, adalah salah satu dari empat hewan suci Tiongkok. Ini dianggap yang paling lama hidup di antara hewan dan dapat meramalkan masa depan. Orang-orang Cina menganggapnya sebagai 
simbol umur panjang. Pada zaman kuno, ketika acara-acara besar diadakan, para syaman biasa membakar kulit kura-kura untuk menilai nasib baik atau buruk dari celahnya. Pada awalnya, Xuanwu merujuk pada kura-kura yang memberikan ramalan: kura-kura memiliki punggung hitam, dan dikatakan memiliki kemampuan untuk memasuki dunia bawah untuk menanyakan tentang peristiwa yang akan datang. Setelah mendapatkan jawabannya, ia akan kembali menunjukkan jawabannya dengan menggunakan beberapa tanda tertentu. Kemudian, biasanya digambarkan sebagai kura-kura dan ular, khususnya dengan ular melingkar di sekitar kura-kura. Saat kura-kura hidup di air, ia menjadi dewa air; karena kura-kura menikmati umur panjang, maka Xuanwu menjadi simbol umur panjang; karena dunia bawah dikatakan berada di utara, orang-orang di Dinasti Shang akan menghadap ke utara ketika mempraktikkan ramalan, dan dengan demikian Xuanwu menjadi dewa utara. Media kelenteng Hok Lay Kiong melakukan ritual ini dengan menggunakan alat peraga seperti bendera atau pedang, yang melambangkan identitas Hian Thian Siang Tee. Meskipun hewan sebagai totem tidak ditampilkan dalam tradisi ini, namun tetap terkait dengan penggunaan totem sebagai identitas komunal.

\section{Kesimpulan}

Praktik penghormatan dewa dikatakan sebagai tradisi yang diciptakan karena dibentuk oleh unsur-unsur pembentuk yang bersumber dari tradisi aslinya. Dengan menelusuri proses penemuan tradisi Hobsbawm dari segi sakral dan profan Durkheim serta kaitannya dengan totemisme, terbukti bahwa tradisi yang diciptakan ini memiliki bentuk dan fungsi baru. Fungsi asli tradisi adalah untuk memperkuat identitas, tetapi fungsi baru dari tradisi yang diciptakan kembali tampaknya merupakan fungsi integratif.

Penghotrmatan terhadap dewa-dewa yang diadakan di kelenteng Hok Lay Kiong menunjukkan bahwa kelenteng merupakan pusat kegiatan yang memiliki fungsi tradisional, ritual, spiritual, kontrol sosial, dan hiburan. Tradisi ciptaan yang dilakukan dalam perayaan hari ulang tahun dewa (sejit) merupakan sesuatu yang baru yang diciptakan oleh masyarakat dalam suatu masyarakat atau kelompok sosial tertentu untuk berbagai tujuan. Tradisi yang ditemukan dalam tradisi penghormatan dewa khususnya pada festival sejit, disebabkan tidak adanya aturan baku atau standar dalam sistem kepercayaan Tionghoa. Fleksibilitas ini mengarah pada proses penemuan yang mudah. Kekuasaan atau kewenangan yang ada, dalam hal ini pengurus atau yayasan memungkinkan terjadinya penemuan tradisi. Penemuan tradisi ini juga terjadi dalam upaya untuk 
menarik minat atau perhatian masyarakat agar lebih populer di masyarakat. Masyarakat pura melakukan proses penemuan tradisional sehingga tradisi penghormatan dewa menjadi lebih menarik, dan disukai lebih populer, melalui penampilan pertunjukan hiburan di festival.

\section{Daftar Referensi}

Akintan, O. A. (2013). Powerful and Powerless: Women in Religion and Culture in the Traditional Ijebu Society. Journal of Social Science, 3 (22).

Chau, Adam Yuet (2011). Religion in Contemporary China, Revitalization and Innovation. Routledge Taylor and Francis Group, London and New York

Clart, P. (2007). The Concept of "Popular Religion" In The Study of Chinese Religions: Retrospect and Prospects. The Forth Fu Jen University International Sinological Symposium: Research on Religions in China: Status Quo and Perspectives; Symposium Papers, 台北縣新 市: 輔大出版 社, 2007 , pp. 166-203 (English version) and pp. 208-237 (Chinese version).

De Groot (1910). The Religious System of China, Its Ancient Forms, Evolution, History and Present Aspect. Manners, Customs and Social Institutions Connected Therewith

Durkheim, Emile (1965). The Elementary Forms of The Religious Life, The Free Press, New York.

Fan, Lizhu, Chen Na (2012) Zhongguo Minjian Xinyang Ji Qi Xiandai Jiazhi de Yanjiu (Research on Popular Belief in China and on its Current Relevall), Annual Report on China's Religion. Beijing

Hartati, Celerina Dewi (2017). God's Birthday Festival as a Temple Festival Variation in Chinese Indonesian Tradition, Chinese Business Review. Volume 16, Number 10. October.

Hobsbawm, Eric dan Terence Ranger (ed) (1983) The Invention of Tradition, Cambridge University Press

$\mathrm{Hu}$, Anning, Yang Fenggang (2014). Trajectories of Folk Religion in Deregulated Taiwan, an Age, Period, Cohort Analysis. Chinese Sociological Review Vol.46, no.3, pp 80-100.

Lee, Raymond LM Continuity and Change in Chinese Spirit Mediumship in Urban Malaysia, In: Bijdragen tot de Taal-, Land- en Volkenkunde 142 (1986), no: 2/3, Leiden, 198-214 KITLV, Royal Netherlands Institute of Southeast Asian and Caribbean Studies.

Rudyansjah, Tony (2015) Emile Durkheim Pemikiran Utama dan Percabangannya Ke Radcliffe Brown, Fortes, Levi Strauss, Turner, dan Holbraad, Jakarta, Penerbit Buku Kompas 
Shahab, Yasmine Zaki (2004) Identitas dan Otoritas, Rekonstruksi Tradisi Betawi, Laboratorium Antropologi FISIP UI, Jakarta

Soothill, William Edward (1913). The Three Religion of China, Oxford

Teiser, Stephen F. Popular Religion, The Journal of Asian Studies Vol.54 No.2 May 1995 (378395) The Concept of Popular Religion in the Study of Chinese Religion: Restrospect and Prospect in The Fourth Fu Jen University Sinological Symposium Research on Religious in China, Furen Daxue Chubanshe (2007)

Thompson, Laurence G (1969). Chinese Religion: An Introduction, Dickenson Publishing Company, Inc. Belmont, California

Tsai, L Lily (2002, July) Cadres, Temple and Lineage Institusion and Governance in Rural China. The China Journal, No. 48, pp. 1-27.

Turner, Bryan S (1991) Religion and Social Theory, Sage Publications Ltd (2003) Agama dan Teori Sosial, IRCiSoD, Yogyakarta,

Weller, R. P. (1987). Unities and Diversities in Chinese Religion. London: The Macmillan Press Ltd.

Yang, CK (1961) Religion in Chinese Society, University of California Press

Yang, Fenggang (2012) Religion in China Survival and Revival Under Communist Rule, New York: Oxford University Press

Yue, Yongyi (2014) Holding Temple Festivals at Home of Doing-Gooders :Temple Festivals and Rural Religion in Contemporary China, Cambridge Journal of China Studies Vol 9 No.1. 